\title{
Genetic diversity and population structure of date palms (Phoenix dactylifera L.) in Ethiopia using microsatellite markers
}

\author{
Workia Ahmed ${ }^{1,2^{*}}$, Tileye Feyissa ${ }^{1}$, Kassahun Tesfaye ${ }^{1,3}$ and Sumaira Farrakh ${ }^{4}$
}

\begin{abstract}
Background: Date palm tree (Phoenix dactylifera L.) is a perennial monocotyledonous plant belonging to the Arecaceae family, a special plant with extraordinary nature that gives eminent contributions in agricultural sustainability and huge socio-economic value in many countries of the world including Ethiopia. Evaluation of genetic diversity across date palms at DNA level is very important for breeding and conservation. The result of this study could help to design for genetic improvement and develop germplasm introduction programmes of date palms mainly in Ethiopia.

Results: In this study, 124 date palm genotypes were collected, and 10 polymorphic microsatellite markers were used. Among 10 microsatellites, MPdCIR085 and MPdCIR093 loci showed the highest value of observed and expected heterozygosity, maximum number of alleles, and highest polymorphic information content values. A total of 112 number of alleles were found, and the mean number of major allele frequency was 0.26 , with numbers ranging from 0.155 (MPdCIR085) to 0.374 (MPdCIR016); effective number of alleles with a mean value of 6.61, private alleles ranged from 0.0 to 0.65 ; observed heterozygosity ranged from 0.355 to 0.726 ; expected heterozygosity varied from 0.669 to 0.906 , polymorphic information content with a mean value of 0.809 ; fixation index individuals relative to subpopulations ranged from 0.028 for locus MPdCIR032 to 0.548 for locus MPdCIR025, while subpopulations relative to total population value ranged from - 0.007 (MPdCIR070) to 0.891 (MPdCIR015). All nine accesstions, neighbour-joining clustering analysis, based on dissimilarity coefficient values were grouped into five major categories; in population STRUCTURE analysis at highest $\mathrm{K}$ value, three groups were formed, whereas DAPC separated date palm genotypes into eight clusters using the first two linear discriminants. Principal coordinate analysis was explained, with a $17.33 \%$ total of variation in all populations. Generally, the result of this study revealed the presence of allele variations and high heterozygosity (>0.7) in date palm genotypes.

Conclusions: Microsatellites (SSR) are one of the most preferable molecular markers for the study of genetic diversity and population structure of plants. In this study, we found the presence of genetic variations of date palm genotypes in Ethiopia; therefore, these genetic variations of date palms is important for crop improvement and conservation programmes; also, it will be used as sources of information to national and international genbanks.
\end{abstract}

Keywords: Date palm (Phoenix dactylifera L.), Genetic diversity, Ethiopia, Microsatellites, Polymorphism, Population structure

\footnotetext{
* Correspondence: workia.ahmed@aau.edu.et; workia.ahmed@yahoo.co.uk;

ahmedworia@gmail.com

${ }^{1}$ Institute of Biotechnology, Addis Ababa University, Addis Ababa, Ethiopia

${ }^{2}$ Department of Biology, Wolkite University, Wolkite, Ethiopia

Full list of author information is available at the end of the article
}

\section{Springer Open}

(c) The Author(s). 2021 Open Access This article is licensed under a Creative Commons Attribution 4.0 International License, which permits use, sharing, adaptation, distribution and reproduction in any medium or format, as long as you give appropriate credit to the original author(s) and the source, provide a link to the Creative Commons licence, and indicate if changes were made. The images or other third party material in this article are included in the article's Creative Commons licence, unless indicated otherwise in a credit line to the material. If material is not included in the article's Creative Commons licence and your intended use is not permitted by statutory regulation or exceeds the permitted use, you will need to obtain permission directly from the copyright holder. To view a copy of this licence, visit http://creativecommons.org/licenses/by/4.0/. 


\section{Background}

Date palm tree (Phoenix dactylifera L.) is a diploid plant with $2 n=36$ chromosome number, a perennial monocotyledonous plant belonging to the Arecaceae family [1, 2]. It is one of the oldest known fruit-bearing tree crops with extensive cultivation and utilization in North Africa and Middle East for at least 5000 years and believed to have originated in Mesopotamia [2-5]. Date palms have a great socio-economic impact and an eminent contribution in agricultural sustainability in many arid and semiarid parts of the world $[1,6]$. It is a multipurpose tree having food, industrial, commercial, medicinal and ornamental values $[7,8]$.

Date fruits have high nutritional value and contain about $70 \%$ sugar, essential vitamins and minerals, and different value-added products are produced [9]. Different parts of the date palm are used for different purposes: leaves are used for making roofs, mats, staple dishes, hand fans, baskets, packaging material, hats, ropes, fences and animal fodder [10]; trunks are used to construct houses, hives and bridges, and used as packing material [11]; terminal buds and young leaves can be cooked as vegetables, while rachises are used for paper making $[12,13]$. Due to the extraordinary nature of the tree with its long-term productivity, the date palm tree is termed as the "tree of life", "Bread of the Desert" [14] and the sacred tree [15].

Date palm is distributed throughout the Middle East, North Africa, South Sahel, areas of East and South Africa, and some parts of Europe and USA [2, 16, 17]. Date palm has been introduced to Ethiopia from Middle East countries approximately 200 years ago by Arabian traders [18]. Cultivation of date palm began in Afar region particularly at Afambo and Asayta and other places nearby Awash River and then spread to Errer Gota and Dredawa areas $[19,20]$. Date farms of these areas are mainly used for local consumption and income sources through treading in nearby towns. In these areas, different unknown varieties of date fruits are produced which have red and yellow colours with different fruit shapes. In Ethiopia, around 14 known varieties have been introduced from other countries for the last 8 years and have been cultivated in three places: Humodoyta site (Afambo), Asayta and Melka Werer agricultural research centre (Melka Werer) for adaptation and improvement programme.

Evaluations of genetic diversity of date palm varieties at DNA level have great value in the date palm's genetic improvement and conservation program. However, to date in Ethiopia, there was no research studied on genetic diversity and population structure of date palms. DNA typing has proven to be the most convenient method for screening variability between plant varieties, analysing genetic diversity and determining phylogenetic relationships among plants [17]. Many studies have been conducted to identify date palm genotypes using morphological traits and biochemical markers. However, using these markers alone, detection of genetic variation among genotypes is unreliable because these markers have been influenced by environmental factors and also show low levels of polymorphism [2, 17, 21]. Different DNA markers have been applied to analyse the genetic relationship of date palm cultivars in many countries such as in Egypt [22, 23], Tunisia [4, 24], Morocco [3], Nigeria [25], Pakistan [2] and Syria [26]. It is well known that microsatellite markers are still one of the most powerful molecular tools due to their nature and reproducibility for assessment of genetic diversity, population structure and differentiation. Therefore, the objective of the present research aimed to assess the genetic diversity and population structure within date palm genotypes collected on different locations and early introduced date palm varieties using microsatellite markers.

\section{Methods \\ Sampling and DNA extraction}

During the time of fruiting, a total of 124 date palm samples both females and males that were collected in Afar and Somalia regions of Ethiopia (Fig. 1) which included early introduced date palm varieties collected from Afambo district specifically located at Humodoyta Kebele (in vitro date palm adaptation farm), and information related to data collection of all samples is available in detail as additional file with a manuscript (in Additional file 1 Table 1). Young and yellowish date palm leaf samples were collected from offshoots, cut into pieces and preserved in silica gel. The dried leaves were ground using liquid nitrogen and acidic sterilised sand. Genomic DNA was extracted using the CTAB method in $100 \mathrm{ml}$ of CTAB buffer $(\mathrm{pH} 8.0)$ containing $2 \%$ of Cetyltrimethylammonium bromide, $4 \mathrm{ml}$ of $20 \mathrm{mM}$ EDTA, $4 \mathrm{ml}$ of $100 \mathrm{mM}$ Tris- $\mathrm{HCl}$ (pH 8.0), $8 \mathrm{~g}$ of $1.4 \mathrm{M}$ $\mathrm{NaCl}$ and $0.1 \% \quad \beta$-mercaptoethanol. To test genome DNA quality, DNA $(3 \mu \mathrm{l})$ was ran on $1 \%$ agarose gel using 0.5X TAE buffer, $90 \mathrm{~V}, 150 \mathrm{~A}, 50 \mathrm{~W}$ for $30 \mathrm{~min}$ set of the gel electrophoresis programme and stained with ethidium bromide solution and then illuminated under UV lights, and photographs were captured. DNA concentrations were also determined using a Gene Quant spectrophotometer.

\section{Polymerase chain reaction (PCR) amplification}

A total of 10 simple sequence repeat (SSR) primers developed by [27] were used (Table 1) to amplify the isolated DNA. For PCR amplifications, $15-\mu \mathrm{l}$ PCR reaction mixtures containing 100 ng DNA $(1 \mu \mathrm{l}), 10 \times$ PCR buffer $(1.5 \mu \mathrm{l}), 25 \mathrm{mM} \mathrm{MgCl} 2(1.2 \mu \mathrm{l}), 10 \mathrm{mM}$ dNTPs mixes $(0.3 \mu \mathrm{l}), 20 \mu \mathrm{M}$ of forward and reverse primers $(1 \mu \mathrm{l}), 9.5$ 


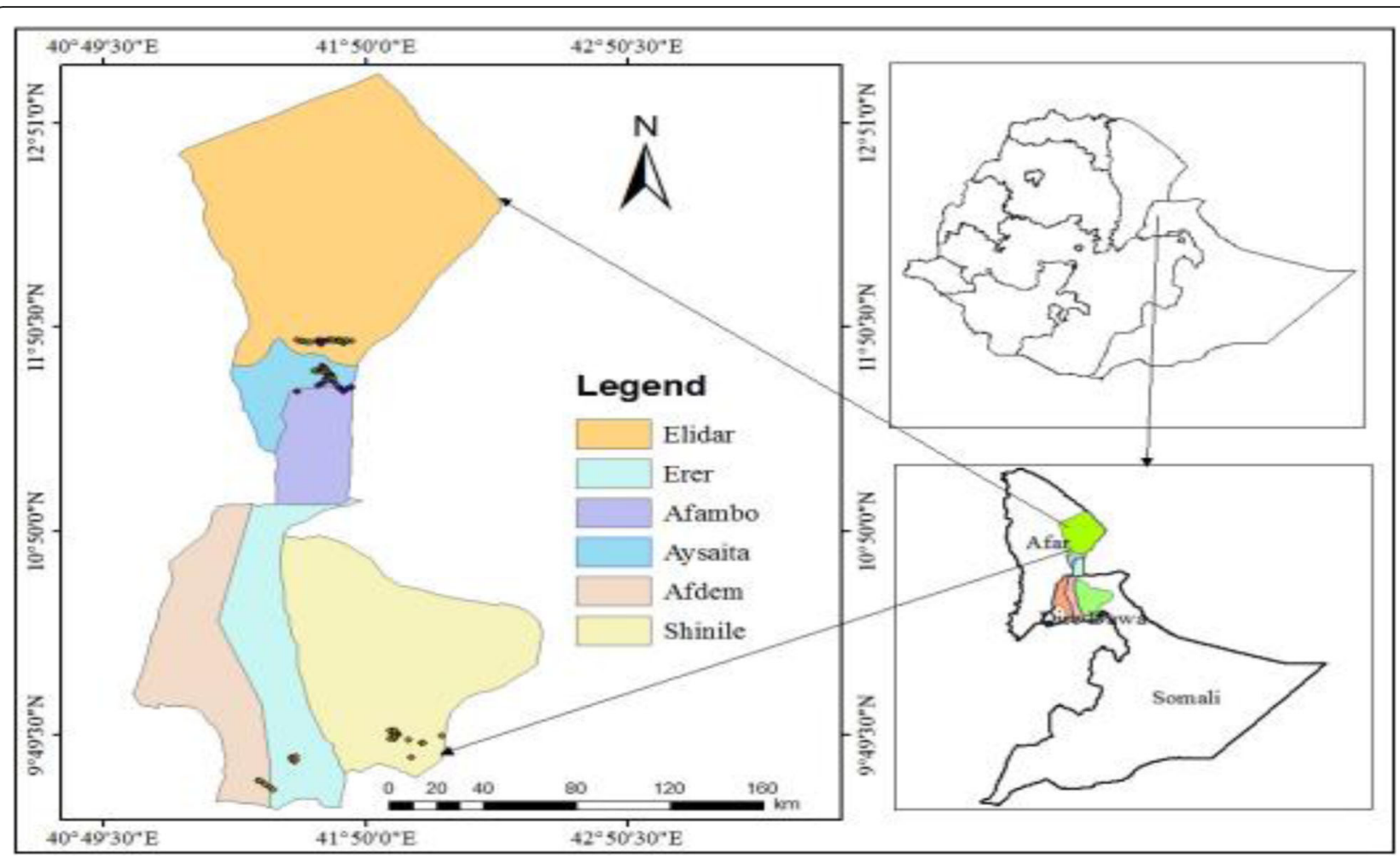

Fig. 1 Geographical location and distribution date palm samples used in this study based on GPS system (black dots on map represent location of date palm trees)

Table 1 Microsatellite/SSR primers used for this study

\begin{tabular}{|c|c|c|c|c|c|}
\hline No. & Primer name & Primer sequences & Repeated motif & Size range (bp) & Annealing temperature $\left({ }^{\circ} \mathrm{C}\right)$ \\
\hline 1 & MPdCIR010 & $\begin{array}{l}\text { F: ACCCCGGACGTGAGGTG } \\
\text { R: CGTCGATCTCCTCCTTTGTCTC }\end{array}$ & $(G A) 22$ & $142-162$ & 52 \\
\hline 2 & MPdCIR015 & $\begin{array}{l}\text { F: AGCTGGCTCCTCCCTTCTTA } \\
\text { R: GCTCGGTTGGACTTGTTCT }\end{array}$ & $(G A) 15$ & $144-156$ & 52 \\
\hline 3 & MPdCIR016 & $\begin{array}{l}\text { F: AGCGGGAAATGAAAAGGTAT } \\
\text { R:ATGAAAACGTGCCAAATGTC }\end{array}$ & $(G A) 14$ & $142-166$ & 52 \\
\hline 4 & MPdCIR025 & $\begin{array}{l}\text { F:GCACGAGAAGGCTTATAGT } \\
\text { R: CCCCTCATTAGGATTCTAC }\end{array}$ & $(G A) 22$ & $220-272$ & 52 \\
\hline 5 & MPdCIR032 & $\begin{array}{l}\text { F: CAAATCTITGCCGTGAG } \\
\text { R:GGTGTGGAGTAATCATGTAGTG }\end{array}$ & $(G A) 19$ & $302-320$ & 52 \\
\hline 6 & MPdCIR050 & $\begin{array}{l}\text { F: CTGCCATTTCTTCTGAC } \\
\text { R: CACCATGCACAAAAATG }\end{array}$ & $(G A) 21$ & $172-260$ & 52 \\
\hline 7 & MPdCIR070 & $\begin{array}{l}\text { F: CAAGACCCAAGGCTAAC } \\
\text { R: GGAGGTGGCTTITGTAGTAT }\end{array}$ & $(\mathrm{GA}) 17$ & $200-250$ & 52 \\
\hline 8 & MPdCIR057 & $\begin{array}{l}\text { F: AAGCAGCAGCCCTTCCGTAG } \\
\text { R: GTTCTCACTCGCCCAAAAATAC }\end{array}$ & $(G A) 20$ & $250-310$ & 52 \\
\hline 9 & MPdCIR085 & $\begin{array}{l}\text { F: GAGAGAGGGTGGTGTTATT } \\
\text { R: TTCATCCAGAACCACAGTA }\end{array}$ & $(G A) 29$ & $166-244$ & 52 \\
\hline 10 & MPdCIR093 & $\begin{array}{l}\text { F: CCATTATCATTCCCTCTCTTG } \\
\text { R: CTTGGTAGCTGCGTTTCTTG }\end{array}$ & $(\mathrm{GA}) 16$ & $175-227$ & 52 \\
\hline
\end{tabular}


$\mu \mathrm{l}$ of PCR grade water, $5 \mathrm{U}$ Taq DNA polymerase $(0.5$ $\mu \mathrm{l})$. All PCR amplifications were performed in thermal Cycler (Buio-Rad) with an initial denaturation step at 94 ${ }^{\circ} \mathrm{C}$ for $5 \mathrm{~min}$ and followed by 35 cycles denaturation at $94{ }^{\circ} \mathrm{C}$ for $30 \mathrm{~s}$, annealing at $52{ }^{\circ} \mathrm{C}$ for $1 \mathrm{~min}$, extension at $72{ }^{\circ} \mathrm{C}$ for $30 \mathrm{~s}$, final extension at $72{ }^{\circ} \mathrm{C}$ for $5 \mathrm{~min}$ and hold period at $4{ }^{\circ} \mathrm{C}$. The PCR products were separated using $1.5 \%$ agarose gels and stained in ethidium bromide solution and then illuminated under UV lights to be taken photographs. The 50 bp DNA ladder (Bio tools) was used to estimate the approximate molecular size of DNA fragments of PCR products (Additional file 4 Figure 1a-e).

\section{Data analysis}

Amplified DNA fragments produced in each microsatellite locus was manually recorded (see Additional file 2 Table 2). Genetic diversity parameters, i.e. expected heterozygosity $(\mathrm{He})$, observed heterozygosity $(\mathrm{Ho})$, observed number of alleles $(\mathrm{Na})$, effective number of alleles $(\mathrm{Ne})$, private alleles per locus, Shannon information index (I) and $\mathrm{Nm}$ (Gene flow estimated from Fst $=0.25(1-$ Fst $) /$ Fst), were calculated by using Popgen 32 version 1.31 [28] and GenAlEx version 6.5 [29] softwares. Major allele frequency (MAF) and number of genotypes (NG) per locus was performed using Power Marker software version 3.25. Polymorphic information content (PIC) of each locus was computed by Curves software version 3.0.7 and the fixation index (Fis, Fst, Fit) were calculated using Arlequin software version 3.5.2.2. Principal coordinate analysis ( $\mathrm{PCoA}$ ) was conducted from distance matrix of each accession using GenAlEx software. Ne's genetic identity and distance was also performed by popgen32 software. Darwin software, version 6.0.21 was used to construct a dendrogram using the neighbourjoining (NJ) algorithm based on dissimilarity matrix and by computing bootstrap value over 1000 replicates. Population genetic structure was analysed based on Bayesian clustering using STRUCTURE 2.3.4 [30] to define the number of clusters in the dataset (i.e. ranging from $K 1$ to $K 10$ ). The admixture ancestry model and correlated allele frequency model were used to perform a Markov chain Monte Carlo simulation algorithm (MCMC). The length of the burn-in period was set to 100,000; MCMC after the burn-in period was set to 200, 000 , and was run 10 times for each $K$ to estimate $K$ values. Optimal $K$ value among $K$ groups was determined based on [31] the method using STRUCTURE HARVESTER [32] online website. The result files obtained from STRUCTURE HARVESTER was also analysed by CLUMPP software online website [33] to align the clusters across replicates and to display clusters in each $K$ drawn as coloured box plots.
Discriminant analysis of principal components (DAPC) and two-locus linkage disequilibrium (LD) analysis

In addition to STRUCTURE analysis, we performed DAPC, an assumption-free multivariate clustering method [34] using the $R$ package 'adegenet' [35] to determine genetic structure date palm genotypes among districts. The optimal number of clusters was inferred using k-means analysis [35] of principal component (PC)-transformed SSR data, and Bayesian information criterion (BIC) was used to assess the best supported model (i.e. the number and nature of clusters). For the DAPC, eight clusters were chosen because they had the lowest value according to the BIC criterion, and 20 PCs were retained. We also calculated Ohta's variance components of linkage disequilibrium [36] of $\mathrm{D}_{\mathrm{IS}}{ }^{2}$ (the average disequilibrium within subpopulations), $\mathrm{D}_{\mathrm{ST}}{ }^{2}$ (the contribution to the overall disequilibrium caused by differences in allele frequencies among subpopulations), $\mathrm{D}_{\mathrm{ST}}{ }^{2}$ (the variance of the correlation of linkage disequilibrium of one population relative to a total population) and $\mathrm{D}_{\text {IS }}{ }^{2}$ (the variance of the correlation within population relative to that of the total population) using Popgen32 version 1.31 .

\section{Results}

\section{SSR marker and its allelic diversity}

A wide range of allele variants were observed from each locus (Table 2). A total of 112 alleles were amplified with an average of 11.0 from all loci and a minimum (5.0) by MPdCIR032 and a maximum (16.0) number of alleles were revealed by MPdCIR085 and MPdCIR093 loci. The mean number of major allele frequency was 0.26 , with numbers ranging from 0.155 (MPdCIR085) to 0.374 (MPdCIR016). All loci 307 genotypes were identified totally, and the number of genotypes per locus ranged from 7 (MPdCIR032) to 47.0 (MPdCIR085). The mean effective number of alleles was 6.61 ranging from 3.0 (for MPdCIR032) to 10.6 (for MPdCIR085). All SSR markers in this study was found to be highly informative with a PIC value $\geq 0.50$ of which MPdCIR085 showed the highest PIC (0.899), while MPdCIR032 showed the lowest PIC (0.597) with an average of 8.09.

\section{Genetic diversity analysis}

In this study, high genetic diversity was shown among nine date palm accessions represented by a total of 124 genotypes. The genetic variation was estimated by observed heterozygosity (Ho), expected heterozygosity $(\mathrm{He})$ and fixation index (Fis, Fst, Fit); these are presented in Table 2 and Fig. 2. The values of observed heterozygosity ranged from 0.355 for the locus MPdCIR025 to 0.726 for the locus MPdCIR093 with a mean value of 0.661 . The highest expected heterozygosity value of 0.906 (for MPdIC085), lowest value of 0.699 (for MPdCIR032) and 
Table 2 Genetic diversity analysis of 10 polymorphic SSR markers for 124 date palm genotypes

\begin{tabular}{|c|c|c|c|c|c|c|c|c|c|c|c|}
\hline Locus & MAF & NG & $\mathrm{Na}$ & $\mathrm{Ne}$ & Ho & $\mathrm{He}$ & Fis & Fst & Fit & $\mathrm{Nm}$ & PIC \\
\hline MPdCIR010 & 0.183 & 40.0 & 12 & 7.94 & 0.669 & 0.874 & $0.209^{* *}$ & $0.040^{*}$ & $0.241^{* *}$ & 3.148 & 0.863 \\
\hline MPdCIR015 & 0.281 & 19.0 & 7 & 5.1 & 0.645 & 0.804 & $0.133^{*}$ & $0.891^{* *}$ & $0.210^{* *}$ & 2.057 & 0.776 \\
\hline MPdCIR016 & 0.374 & 29.0 & 11 & 4.94 & 0.508 & 0.798 & $0.356^{* *}$ & 0.018 & $0.368^{* *}$ & 3.443 & 0.779 \\
\hline MPdCIR025 & 0.297 & 30.0 & 13 & 6.3 & 0.355 & 0.84 & $0.548^{* *}$ & $0.078^{* *}$ & $0.584^{* *}$ & 1.824 & 0.823 \\
\hline MPdCIR032 & 0.369 & 7.0 & 5 & 3 & 0.645 & 0.669 & 0.028 & 0.012 & 0.04 & 5.109 & 0.597 \\
\hline MPdCIR050 & 0.239 & 37.0 & 11 & 7.1 & 0.694 & 0.86 & $0.190^{* *}$ & 0.01 & $0.198^{* *}$ & 4.523 & 0.845 \\
\hline MPdCIR057 & 0.284 & 30.0 & 12 & 5.9 & 0.468 & 0.832 & $0.398^{* *}$ & $0.079 * *$ & $0.446^{* *}$ & 1.637 & 0.812 \\
\hline MPdCIR070 & 0.304 & 27.0 & 9 & 5.6 & 0.694 & 0.822 & $0.165^{* *}$ & -0.007 & $0.157^{* *}$ & 6.432 & 0.803 \\
\hline MPdCIR085 & 0.155 & 47.0 & 16 & 10.6 & 0.71 & 0.906 & $0.194^{* *}$ & 0.036 & $0.224^{* *}$ & 3.273 & 0.899 \\
\hline MPdCIR093 & 0.179 & 41.0 & 16 & 9.45 & 0.726 & 0.894 & $0.178^{* *}$ & 0.0018 & $0.194^{* *}$ & 4.152 & 0.898 \\
\hline Mean & 0.267 & 30.7 & 11.2 & 6.61 & 0.611 & 0.831 & 0.198 & 0.077 & 0.256 & 3.56 & 0.809 \\
\hline Sum & & 307.0 & 112 & & & & & & & & \\
\hline
\end{tabular}

Exact test significant at ${ }^{*} P<0.05,{ }^{* *} P<0.001$

an average of 0.831 for all loci values were observed. In addition, across the population, high (0.81) and low (0.73) values of heterozygosity were observed in date palm populations collected in Mamulae and Kerebuda; also, the maximum mean numbers of alleles of date palm populations were 8.5 in Mamulae, 7.5 in Humodoyta and 7.5 in early introduced (Fig. 2). Although, in eight populations, a total of 16 private alleles were recorded, and no private alleles were seen in the Berga population (Fig. 2). Population differentiations were also determined by fixation indices (Fis, Fst, and Fit) for each locus with mean values of $0.198,0.077$ and 0.256 , respectively. Fixation index (Fis) individuals relative to subpopulations ranged from 0.028 for locus MPdCIR032 to 0.548 for locus MPdCIR025, while Fst values ranged from - 0.007 (MPdCIR070) to 0.891 (MPdCIR015). From all loci except MPdCIR015, MPdCIR025 and MPdCIR057 showed moderate degree of genotypic differentiation between populations with Fst values of more than 0.05 with significant value at $P<0.001$. The highest

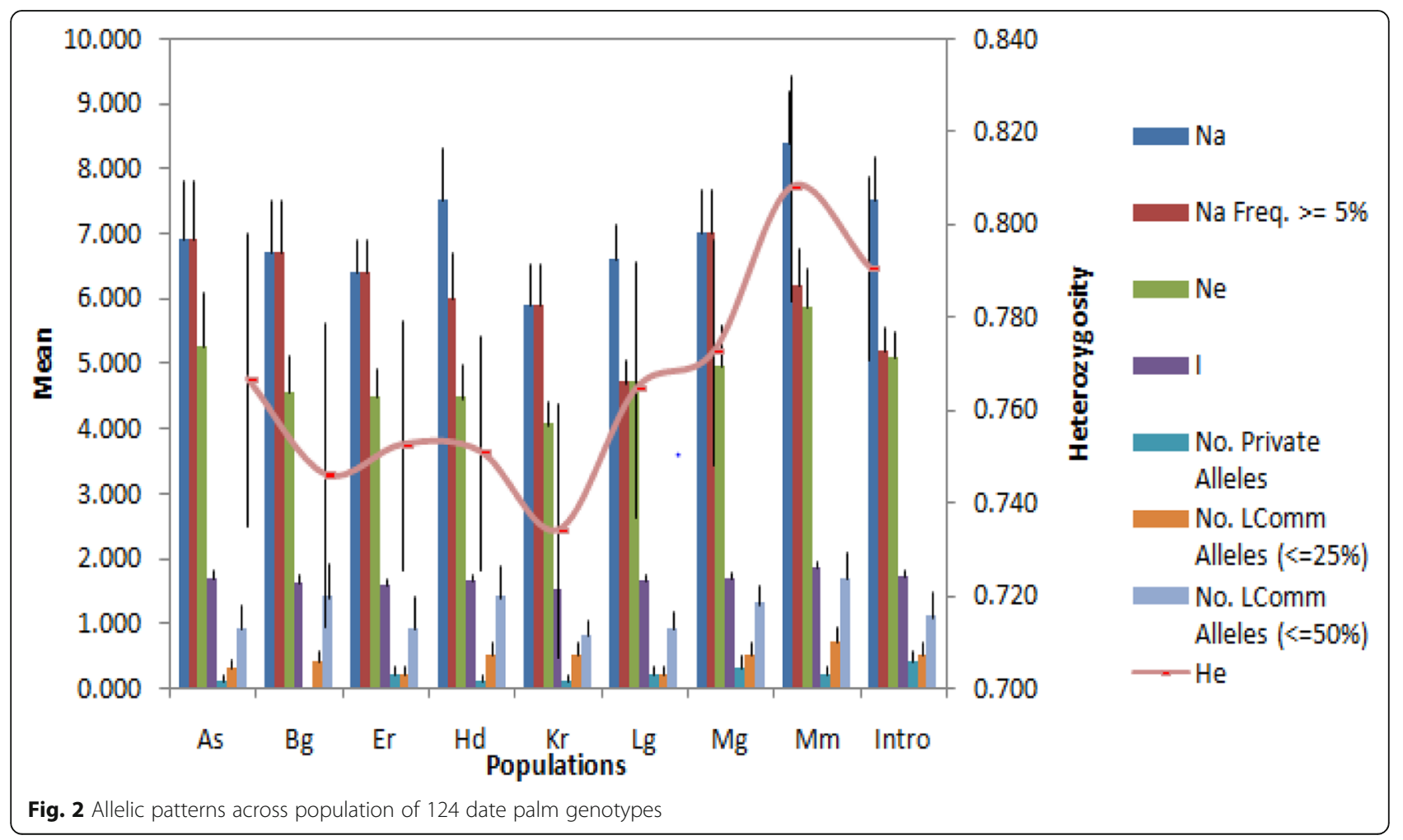


Table 3 Nei's genetic similarity (above diagonal) and genetic distance (below diagonal) between date palm populations

\begin{tabular}{llllllllll}
\hline Pop ID & As & Bg & Er & Hd & Kr & Lg & Mg & Mm & Intro \\
\hline As & $* * * *$ & 0.7299 & 0.7543 & 0.7800 & 0.5838 & 0.7365 & 0.6259 & 0.7752 & 0.7476 \\
Bg & 0.3149 & $* * * *$ & 0.8165 & 0.7727 & 0.5800 & 0.7824 & 0.5990 & 0.7557 & 0.6696 \\
Er & 0.2819 & 0.2027 & $* * * *$ & 0.7478 & 0.5846 & 0.7661 & 0.5933 & 0.7242 & 0.6690 \\
Hd & 0.2485 & 0.2579 & 0.2906 & $* * * *$ & 0.5356 & 0.7281 & 0.6232 & 0.7434 & 0.7416 \\
Kr & 0.5382 & 0.5448 & 0.5369 & 0.6244 & $* * * *$ & 0.6347 & 0.7510 & 0.7795 & 0.5271 \\
Lg & 0.3058 & 0.2454 & 0.2664 & 0.3174 & 0.4546 & $* * * *$ & 0.6892 & 0.8360 & 0.6739 \\
Mg & 0.4686 & 0.5124 & 0.5220 & 0.4728 & 0.2863 & 0.3722 & $* * * *$ & 0.8007 & 0.5575 \\
Mm & 0.2546 & 0.2802 & 0.3227 & 0.2965 & 0.2491 & 0.1791 & 0.2222 & $* * * *$ & 0.7129 \\
Intro & 0.2909 & 0.4011 & 0.4020 & 0.2989 & 0.6403 & 0.3947 & 0.5843 & 0.3384 & $* * * *$ \\
\hline
\end{tabular}

(7.0) and the lowest (4.7) mean values of the number of different alleles with a frequency $\geq 5 \%$ was in Mego and Legaharae, respectively. The mean of number of locally common alleles with a frequency $\geq 5 \%$ found in $25 \%$ of the total populations was ranged from 0.2 (in Errer Gota) to 0.7 (in Mamulae) whereas, the mean number of locally common alleles with a frequency $\geq 5 \%$ found in $50 \%$ of the total population ranged from 0.8 (in Kerebuda) to 1.7 (in Mamulae) (see Fig. 2). The degree of genetic similarity and distance between date palm populations are presented in Table 3. High genetic similarity was observed between Mamulae and Legaharae populations, while low similarity was between early introduced and Kerebuda. On the other hand, among populations we found lowest and highest genetic distance values 0.1791 and 0.6403 between Mamulae and Legaharae and Introduced and Kerebuda respectively. In addition, AMOVA showed that the prevalence of higher percentage genetic variation within individuals (73\%) than among populations (4\%) in Table 4.

\section{Clustering and population genetic structure}

A dendrogram and principal coordinate analysis were made to determine the structural similarity of among and within date palm populations and to predict the genetic difference between them. All genotypes separated into five major clusters (Fig. 3a), and one population is represented by the same colour as coded in the number list (Fig. 3b), and is similarly displayed in a dendrogram. In cluster 1 , twenty eight individuals, cluster 2 thirty four, cluster 3 twenty three, cluster 4 , twenty five and cluster 5 fourteen individuals were grouped as

Table 4 Summary of AMOVA

\begin{tabular}{llllll}
\hline Source & df & SS & MS & Est. Var. & $\%$ \\
\hline Among populations & 8 & 74.394 & 9.299 & 0.159 & $4 \%$ \\
Among individuals & 115 & 575.037 & 5.000 & 0.968 & $23 \%$ \\
Within individuals & 124 & 380.0 & 3.065 & 3.065 & $73 \%$ \\
Total & 247 & 1029.431 & & 4.191 & $100 \%$ \\
\hline
\end{tabular}

members. Clusters 1, 2, 3, and 5 were further subdivided into two subclusters, while cluster 4 was divided into three subclusters. All subclusters further subdivided into many subgroups which represented a clade composed of mixed genotypes of the populations. Half of the genotypes of each Introduced and Humodoyta populations were found together in cluster 1 , whereas others clusters contained mixed genotypes from different populations. PCoA analysis revealed $17.33 \%$ total variation explained by the first 3 axes (Fig. 4a). The distribution of genotypes on the PCoA graph is not separately clustered depending on their accessions; instead, they showed intermixing of genotypes among populations and also similarly displayed on NJ tree. In population STRUCT URE analysis, date palm genotypes from all accessions were segregated into three subpopulations in the Bayesian clustering model using STRUCTURE software version 2.3.4 with the criterion of maximum membership probabilities based on [31] method, (i.e. the delta $K$ value had the highest peak, at $K=3$ (Fig. 4b)). The STRUCT URE output CLUMPP software online displayed light blue, orange and violet colours of bar plots (Fig. 4c) and revealed admixture structure in each date palm population regardless their accessions. The distributions of genotypes on the coordinate axis (Fig. 4a) as well as clustering of genotypes in a NJ tree (Fig. 3) were accord with the result in population STRUCTURE.

\section{Discriminate analysis of principal components and two- locus linkage disequilibrium}

Using the Bayesian model-based approach, the membership probabilities of each date palm individual for the different groups were obtained from DAPC and the results of DAPC analysis. The DAPC separated date palm genotypes into eight clusters based on the first two linear discriminants (Fig. 5 and in Additional file 3 Table 3 ). The DAPC analyses revealed that all of early introduced date palm genotypes except one individual were represented by two genetic clusters (DAPC clusters 4 and 6). This result suggests that these date palm 


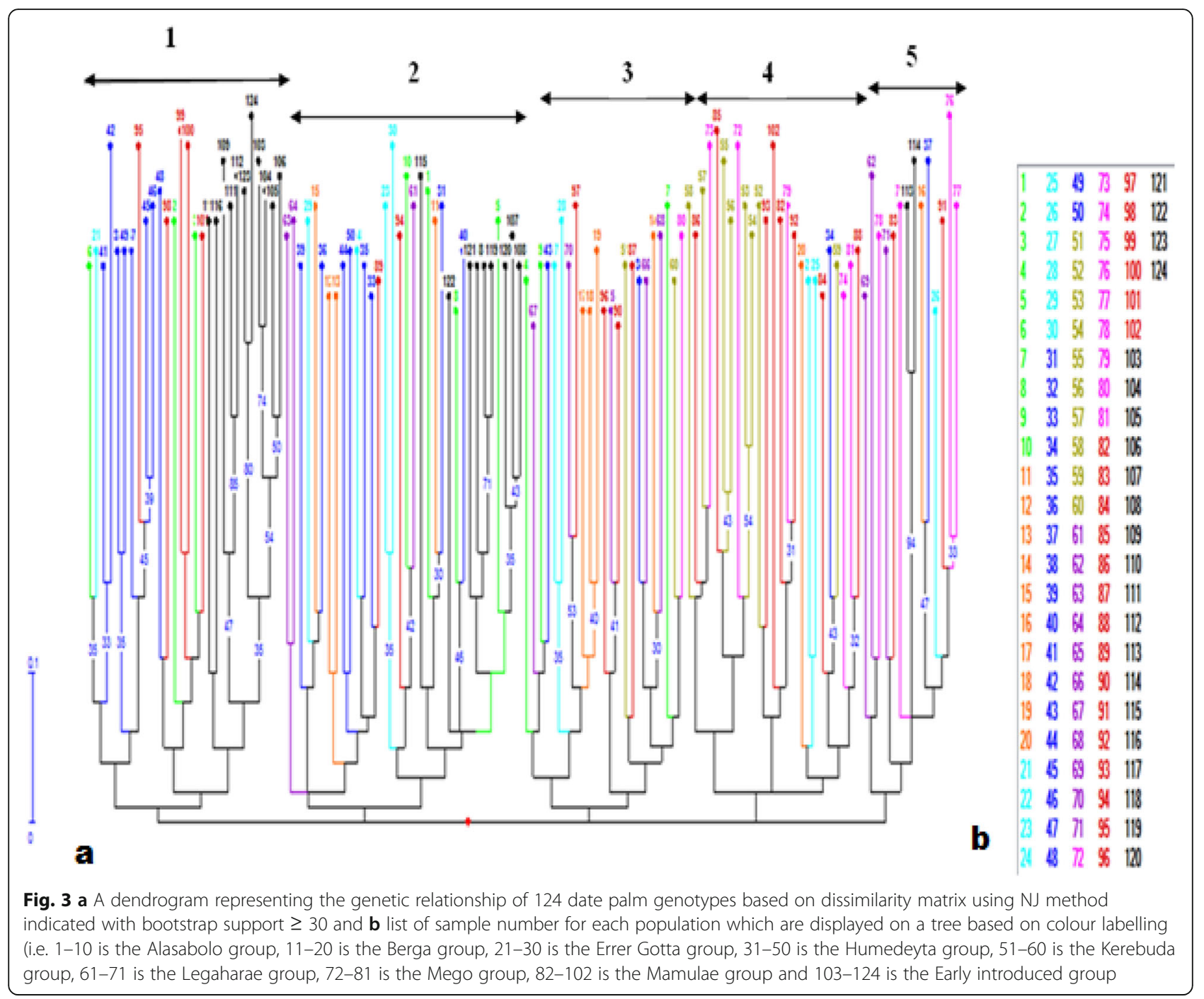

cultivars are genetically distinct groups from others. Besides, the NJ tree pattern showed that these introduced date palms are predominantly found in subcluster of the major clusters 1 and 2 of the $\mathrm{NJ}$ tree; this result is consistent with the DAPC clusters 4 and 6 . The DAPC clusters 1 and 3 only contained 21 and 23 individuals from Afambo and Asayta district respectively, while the DAPC clusters 2, 5, 7 and 8 represented mixed individuals from all districts; i.e. DAPC cluster 2 contained a total of 18 individuals: 3 from Afambo, 12 from Asayta and 3 from Shinile; DAPC cluster 5 comprises a total of 13 genotypes: 3 from Afambo, 1 from Asayta, 1 from Errer, 7 from Shinile and 1 introduced cultivar and DAPC cluster 7 consisted 6 individuals from Afambo, 1 individual from Asayta, 9 individuals from Errer Gota; the DAPC cluster 8 included 7 genotypes from Afambo, 4 genotypes from Asayta and 1 genotype from Shinile districts. In general, the DAPC result showed that individuals were slightly admixed structure as compared with the population STRUCTURE and NJ results. A total of 45 two-locus pairs were analysed to estimate variance components of linkage disequilibrium. The overall average variance of the disequilibrium of the individual compared with the total populations $\mathrm{D}_{\mathrm{IT}}{ }^{2}$ was 0.04681 . A total average of $\mathrm{D}_{\text {IS }}^{\prime}{ }^{2}(0.0435)$ was larger than $\mathrm{D}^{\prime} \mathrm{ST}^{2}$ (0.0033). Besides, the average value of $\mathrm{D}_{\mathrm{ST}}{ }^{2}(0.0265)$ was greater than the average of $\mathrm{D}_{\mathrm{IS}}^{2}$ (0.0201). From the total pairs of loci, only 30 pairs of loci was shown in the dual relationships of $\mathrm{D}_{\mathrm{ST}}{ }^{2}>$ $\mathrm{D}_{\mathrm{IS}}{ }^{2}$ and $\mathrm{D}_{\mathrm{IS}}{ }^{2}>\mathrm{D}^{\prime} \mathrm{ST}^{2}$ in Table 5 . This relation in pairs of loci indicated that nonrandom association of the SSR alleles at particular variable loci was mainly caused by limited migration and random process or genetic drift [36, 37]. However, the rest of the 15 pairs of loci were shown in the dual relationships of $\mathrm{D}_{\mathrm{ST}}{ }^{2}<\mathrm{D}_{\mathrm{IS}}{ }^{2}$ and $\mathrm{D}_{\mathrm{IS}}{ }^{2}<\mathrm{D}^{\prime} \mathrm{ST}^{2}$; this is because gametes with favorable combinations of alleles would increase in every population [36, 37]. 


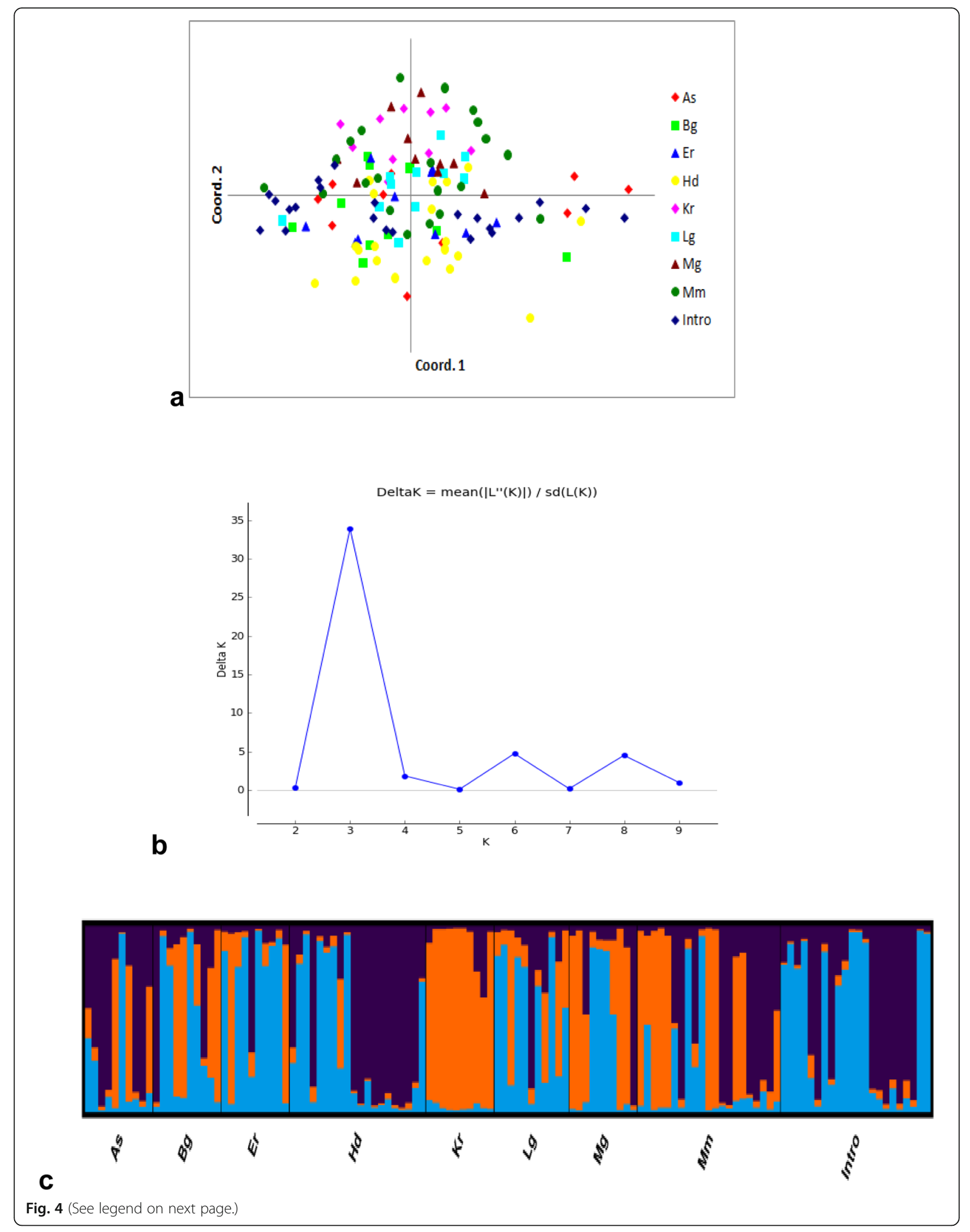


(See figure on previous page.)

Fig. 4 a Two-dimensional plot of principal coordinates analysis of 124 date palm genotypes that represent for nine populations. $\mathbf{b}$ Estimation of population using $\Delta \boldsymbol{K}=$ mean $\left(\left|\boldsymbol{L}^{\prime \prime}(\boldsymbol{K})\right|\right) / \operatorname{sd}(\boldsymbol{L}(\boldsymbol{K}))$ with cluster number $(\boldsymbol{K})$ ranging from 1 to 10 and $\boldsymbol{K}=3$ is the optimal $\boldsymbol{K}$ value based on Evanno et al. (2005) method. c Results of STRUCTURE analysis based on microsatellite data and estimation of genetic structure of the nine populations using $\boldsymbol{K}=3$. Each population is represented by a vertical bar and separated by a black line, partitioned into coloured segments representing the proportion of the individual's genome in the $\boldsymbol{K}$ clusters

\section{Discussion}

The purpose of the present study is to determine the genetic diversity and relationship between date palm genotypes and populations using SSR markers. All of the SSR primers tested in this study demonstrated PIC values from 0.509 to 0.899 ; these are considered to be highly informative markers and the occurrence of allele variations among populations; this is also supported by previous studies [38,39]. A total of 112 alleles were detected from 124 date palm individual samples in

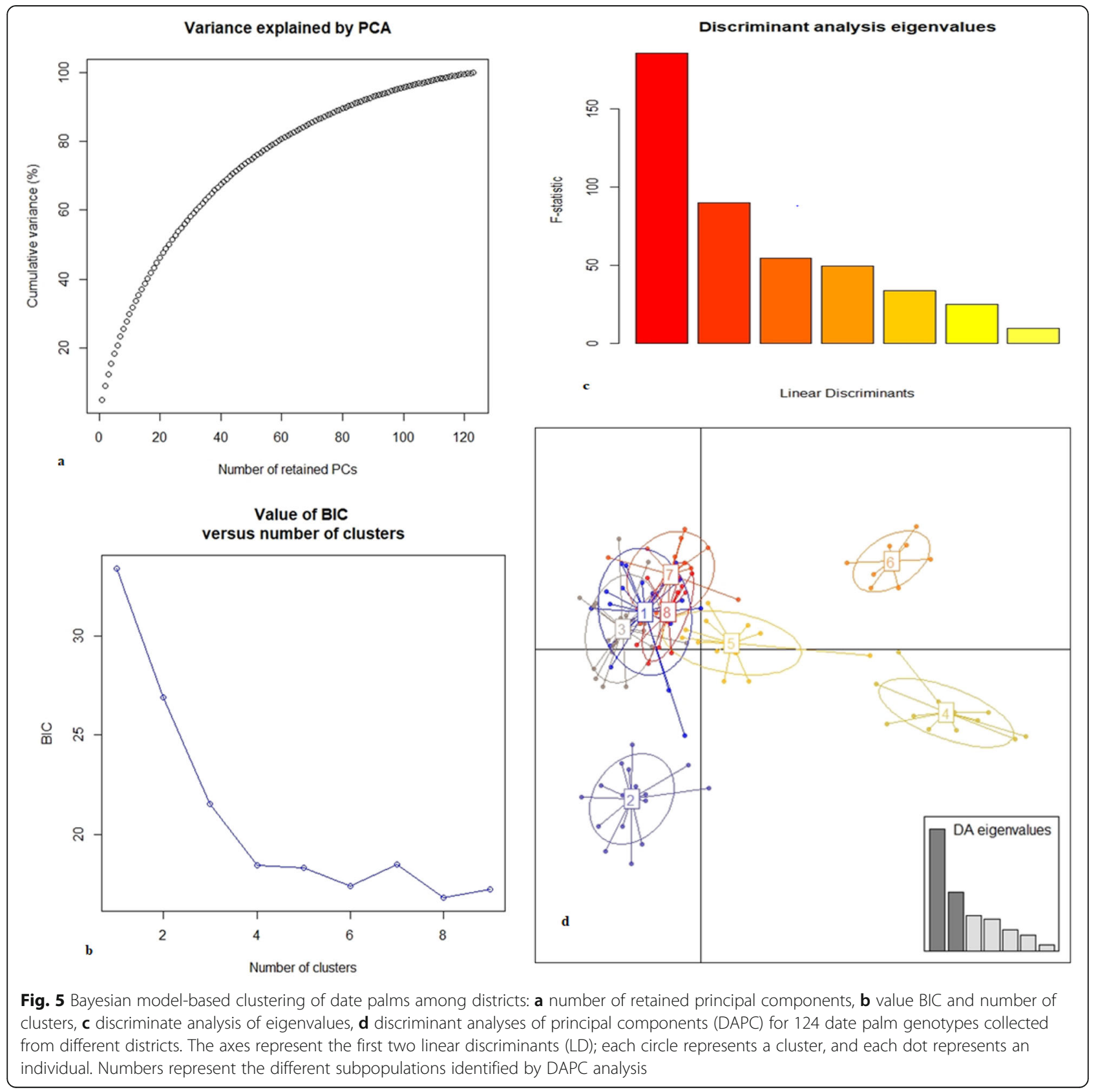


Table 5 Ohta's two-locus analysis of linkage disequilibrium of 10 SSR markers

\begin{tabular}{|c|c|c|c|c|c|}
\hline Locus A-Locus B & $(\mathrm{DIT})^{2}$ & $(\mathrm{DIS})^{2}$ & $\left(D^{\prime} I S\right)^{2}$ & $(\mathrm{DST})^{2}$ & $\left(D^{\prime} S T\right)^{2}$ \\
\hline MPdCIR010-MPdCIR015 & 0.04751 & 0.01856 & 0.04314 & 0.03147 & 0.00437 \\
\hline MPdCIR010-MPdCIR016 & 0.04730 & 0.02264 & 0.04363 & 0.02487 & 0.00367 \\
\hline MPdCIR010-MPdCIR025 & 0.05556 & 0.02375 & 0.05144 & 0.03162 & 0.00412 \\
\hline MPdCIR010-MPdCIR032 & 0.04203 & 0.01575 & 0.03886 & 0.02806 & 0.00317 \\
\hline MPdCIR010-MPdCIR050 & 0.04232 & 0.02251 & 0.03863 & 0.01832 & 0.00369 \\
\hline MPdCIR010-MPdCIR057 & 0.05966 & 0.02227 & 0.05514 & 0.03522 & 0.00452 \\
\hline MPdCIR010-MPdCIR070 & 0.04375 & 0.02477 & 0.03905 & 0.01906 & 0.00470 \\
\hline MPdCIR010-MPdCIR085 & 0.04356 & 0.02536 & 0.03866 & 0.01964 & 0.00490 \\
\hline MPdCIR010-MPdCIR093 & 0.03898 & 0.02103 & 0.03474 & 0.01743 & 0.00423 \\
\hline MPdCIR015-MPdCIR016 & 0.05277 & 0.01889 & 0.04908 & 0.03436 & 0.00369 \\
\hline MPdCIR015-MPdCIR025 & 0.06567 & 0.01806 & 0.06213 & 0.04474 & 0.00355 \\
\hline MPdCIR015-MPdCIR032 & 0.05207 & 0.01177 & 0.05071 & 0.03777 & 0.00136 \\
\hline MPdCIR015-MPdCIR050 & 0.04054 & 0.01585 & 0.03838 & 0.02464 & 0.00216 \\
\hline MPdCIR015-MPdCIR057 & 0.06444 & 0.02086 & 0.06164 & 0.04634 & 0.00280 \\
\hline MPdCIR015-MPdCIR070 & 0.04272 & 0.01720 & 0.04057 & 0.02553 & 0.00214 \\
\hline MPdCIR015-MPdCIR085 & 0.04669 & 0.01901 & 0.04294 & 0.02665 & 0.00375 \\
\hline MPdCIR015-MPdCIR093 & 0.04104 & 0.01604 & 0.03844 & 0.02402 & 0.00260 \\
\hline MPdCIR016-MPdCIR025 & 0.05557 & 0.02307 & 0.05120 & 0.03331 & 0.00437 \\
\hline MPdCIR016-MPdCIR032 & 0.03057 & 0.01013 & 0.02922 & 0.02532 & 0.00136 \\
\hline MPdCIR016-MPdCIR050 & 0.04109 & 0.02180 & 0.03874 & 0.01827 & 0.00235 \\
\hline MPdCIR016-MPdCIR057 & 0.05689 & 0.02261 & 0.05336 & 0.03698 & 0.00353 \\
\hline MPdCIR016-MPdCIR070 & 0.03739 & 0.02041 & 0.03304 & 0.01797 & 0.00435 \\
\hline MPdCIR016-MPdCIR085 & 0.04812 & 0.02370 & 0.04499 & 0.02179 & 0.00313 \\
\hline MPdCIR016-MPdCIR093 & 0.04131 & 0.02302 & 0.03758 & 0.01799 & 0.00373 \\
\hline MPdCIR025-MPdCIR032 & 0.05555 & 0.01314 & 0.05354 & 0.04143 & 0.00201 \\
\hline MPdCIR025-MPdCIR050 & 0.04742 & 0.01989 & 0.04459 & 0.02653 & 0.00283 \\
\hline MPdCIR025-MPdCIR057 & 0.07457 & 0.02512 & 0.06850 & 0.04683 & 0.00608 \\
\hline MPdCIR025-MPdCIR070 & 0.05081 & 0.02290 & 0.04671 & 0.02691 & 0.00411 \\
\hline MPdCIR025-MPdCIR085 & 0.05249 & 0.02404 & 0.04776 & 0.02734 & 0.00473 \\
\hline MPdCIR025-MPdCIR093 & 0.05400 & 0.02914 & 0.04803 & 0.02467 & 0.00597 \\
\hline MPdCIR032-MPdCIR050 & 0.02965 & 0.01014 & 0.02870 & 0.02053 & 0.00095 \\
\hline MPdCIR032-MPdCIR057 & 0.05998 & 0.01488 & 0.05680 & 0.04419 & 0.00317 \\
\hline MPdCIR032-MPdCIR070 & 0.02851 & 0.01240 & 0.02729 & 0.01746 & 0.00121 \\
\hline MPdCIR032-MPdCIR085 & 0.04159 & 0.01533 & 0.03965 & 0.02655 & 0.00194 \\
\hline MPdCIR032-MPdCIR093 & 0.03874 & 0.01532 & 0.03682 & 0.02203 & 0.00191 \\
\hline MPdCIR050-MPdCIR057 & 0.05406 & 0.02282 & 0.05089 & 0.02983 & 0.00317 \\
\hline MPdCIR050-MPdCIR070 & 0.03817 & 0.02197 & 0.03593 & 0.01418 & 0.00223 \\
\hline MPdCIR050-MPdCIR085 & 0.03777 & 0.02190 & 0.03560 & 0.01652 & 0.00218 \\
\hline MPdCIR050-MPdCIR093 & 0.03628 & 0.02347 & 0.02347 & 0.03318 & 0.00310 \\
\hline MPdCIR057-MPdCIR070 & 0.05421 & 0.02165 & 0.05067 & 0.03015 & 0.00353 \\
\hline MPdCIR057-MPdCIR085 & 0.05418 & 0.02473 & 0.04909 & 0.02969 & 0.00511 \\
\hline MPdCIR057-MPdCIR093 & 0.05341 & 0.02510 & 0.04830 & 0.02515 & 0.01443 \\
\hline MPdCIR070-MPdCIR085 & 0.03828 & 0.02089 & 0.03571 & 0.01675 & 0.00257 \\
\hline MPdCIR070-MPdCIR093 & 0.03174 & 0.01794 & 0.02913 & 0.01411 & 0.00261 \\
\hline
\end{tabular}


Table 5 Ohta's two-locus analysis of linkage disequilibrium of 10 SSR markers (Continued)

\begin{tabular}{|c|c|c|c|c|c|}
\hline Locus A-Locus B & $(\mathrm{DIT})^{2}$ & $(\mathrm{DIS})^{2}$ & $\left(D^{\prime} \mid S\right)^{2}$ & $(D S T)^{2}$ & $\left(D^{\prime} S T\right)^{2}$ \\
\hline MPdCIR085-MPdCIR093 & 0.03734 & 0.02203 & 0.03446 & 0.01512 & 0.00288 \\
\hline Overall average & 0.04681 & 0.02009 & 0.04348 & 0.02648 & 0.00332 \\
\hline
\end{tabular}

populations. This exhibits the presence of high genetic diversity within date populations. In this study, number of alleles/ locus varied from 5 to 16 and maximum number of alleles (16) was amplified by MdPCIR085 and MdPCIR093 loci. According to [3], a maximum number of alleles (11) was detected by MdPCIR050; ranging between 4 and 11, whereas [40] reported a number of alleles ranging from 6 to 15 per locus and maximum (15) number of alleles amplified by primer MdPCIR015. The current study showed high genetic diversity among Ethiopian date palm populations may be due to high heterozygosity ( $>0.72$ ).

In this study, NJ tree and principal coordinate analysis outcomes provided clear genetic relationship between unknown date palm varieties and early introduced cultivated date palm varieties. The dendrogram generated five major clusters. Generally, in this study, there was no clear separation among genotypes according to their geographical locations. In cluster one, eight individuals from Humodoyta kebele, five individuals from Mamulae kebele, three individuals from Alassabolo kebele and one individual from Errer Gota were clustered together with these early introduced cultivated date palm varieties (i.e. Sagaii, Jarvis, Khadrawy, Khalas, Medjool Israel and Khayra). Other cultivated varieties (Mdjool England, Shish, Zamli and Ashal Al Hassa) were found in cluster two with mixed individuals from Legaharae, Berga, Humodoyta, Error Gota, Alassabolo and Mamulae populations. Barhee cultivated variety was only found in cluster five incorporated with individuals from other populations. Half of date palm genotypes from Kerebuda population mainly observed in the subcluster of a clade four categories. This result was also supported with results in PCoA and population STRUCTURE analysis (i.e., intermixing distributions of genotypes on principal component axis and admixture structures were observed). The present result of PCoA showed certain match with the previous studies reported by [24, 41], contrary to the report by [38-40, 42]. According to the model-based clustering for genetic structure of date palm individuals, three genetically distinctive subpopulations were presented that were not formed in line with their collection places. The highest mean similarity score was estimated at $K=3$, the most probable clustering of populations was observed at this $K$ level and showed admixture structure among populations. This result displays the date palm populations that have a common genetic background and also they shared common alleles between them. The most differentiated population in this study was observed in Kerebuda population, which showed fewer admixtures than the other populations. Generally, the structure result had shown shared ancestry between unknown date palm genotypes and known date palm cultivars that were early introduced. The admixture result of the present study at $K=3$ is in agreement with those reported by [39, 40, 43]. Similarly, [44] revealed three differentiated date palm memberships at $K=3$ using different SSR as well as four date palm groups at $K=4$ using SNPs. In both markers, they reported the admixture population structure of date palms at best $K$ value of each cluster that was collected from different parts of the world. Intermixing clustering results of date palm genotypes in structure analysis of the present study to some extent coincides with the previous finding at five different $K$ groups that were studied using different SSR primers $[1,41]$. The DAPC results of this study exhibited genetic differentiation between groups while overlooking within-group variation and achieved the best discrimination of individuals into predefined groups. We confirmed maximum likelihood-based clustering results using DAPC method that is considered free of Hardy-Weinberg and linkage disequilibrium assumptions. The DAPC approach relies on discriminant functions that seek to maximize the diversity between clusters while minimizing within-cluster diversity [34]. Due to this reason, DAPC mostly assigned individuals to single clusters [34]. DAPC was suggested as an alternative method to identify and describe clusters of genetically related individuals by analysing complex genetic data and detecting admixed individuals by determining the probability that each individual belonged to each cluster [40, 45].

Overall, the AMOVA result of expected heterozygosity revealed high genetic differentiation within date palm genotypes and the outcome of the NJ tree; PCoA and structure analysis of this study are dominated by admixture structure patterns among populations. This might be due to the codominant nature of microsatellite markers contributed to have high allele's variations per locus as well as high heterozygosity within date palm genotypes due to DNA slippage during the process of DNA replication. DNA slippage is the mutation of microsatellite length during enzymatic replication of microsatellite regions that are usually the result of insertion and deletion of repeats in DNA strands [46, 47]. On the other hand, date palms are dioecious and cross- and 
wind-pollinated plant species. This nature of the palms facilitates broadened genetic variations within date palm genotypes. In the case of cross-pollinating species, it is obvious that within plant populations, they maintain high levels of genetic diversity due to their breeding system [48-50]. Moreover, at date palm collection sites of the current study, there was no integrated management system related to propagation for date palms, i.e. the plants are like wilds (W. Ahmed, personal communication). Consequently, this situation could increase the probability of date palms breeding from seeds rather than offshoots. The date palms germinated by seeds have a dioecious nature, so an increase in the genetic distance between date palm genotypes is expected; also, low rate of gene flow within the population contributes to exhibited high genetic diversity within populations rather than among populations.

\section{Conclusions}

Preliminary research on genetic diversity of plant species is the most essential issue for long-term plant improvement and conservation and development of mechanisms for reduction of plant vulnerability. SSR markers used in the present study revealed high genetic diversity within date palm genotypes and date palm populations. Therefore, this finding contributes input information in genetic relationship between known cultivated date palm varieties and unknown date palm varieties for improvement and conservation programmes. Generally, this study will be an eminent evidence and source of information on genetic diversity of date palms in Ethiopia to regional and international genbanks.

\section{Abbreviations \\ AMOVA: Analysis of molecular variance; CTAB: Cetyl trimethyl ammonium bromide; DNA: Deoxyribonucleic acid; dNTP: Deoxyribonucleotide triphosphate; DAPC: Discriminate analysis of principal components; He: Expected heterozygosity; Ho: Observed heterozygosity; I: Shannon information index; LD: Linkage disequilibrium; MAF: Major allele frequency; Na: Observed number of alleles; Ne: Effective number of alleles; NG: Number of genotype per locus; PCoA: Principal coordinate analysis; PCR: Polymerase chain reaction; PIC: Polymorphic information content; NJ: Neighbour-joining; SSR: Simple sequence repeat}

\section{Supplementary Information}

The online version contains supplementary material available at https://doi. org/10.1186/s43141-021-00168-5

Additional file 1: Table 1 Data information of date palms in Ethiopia during the time of sample collection and cods of samples that were used for analysis.

Additional file 2: Table 2 Microsatellite genotypic data of 124 date palm genotypes using 10 SSR markers.

Additional file 3: Table 3 Proportion of individuals assigned in each DAPC cluster.

Additional file 4: Figure 1 Examples of PCR products obtained by the following SSR primers: a) MPdCIR016, b) MPdCIR050, c) MPdCIR085 and d)
MPdCIR093 e) M: 50 base pairs molecular weight markers used as a reference for scoring in this study.

\section{Acknowledgements}

The World Academy of Sciences (TWAS), Addis Ababa University and Wolkite University for finance support. We thank COMSATS University of Islamabad Department of Biosciences for offering an access for laboratory working of this study. We gratefully acknowledged persons that were assist during laboratory work and sample collection.

\section{Plant specimens}

For the purpose of genetic diversity study, it does not need formal identification of the plant, and also in Ethiopia, there is no national guidelines and legislation to get permission for plant sample collection. But if the research works (e.g., experiment is carried out aboard of Ethiopia), it must need permission from Ethiopian Institute of Biodiversity to travel the collected samples to another country. In this study, all date palm pieces of leaf samples were collected by me and my assistants.

\section{Authors' contributions}

WA carried out sampling, laboratory work, data analysis, and writing of the manuscript. TF and KT did proposal conceptualization and preparation and proofread this manuscript. SF guided laboratory works and edited the manuscript. The authors read and checked the manuscript for publication.

\section{Funding}

This research work was supported by The World Academy of Sciences (TWAS), Addis Ababa University and Wolkite University. The research fund from TWAS was utilized for purchasing laboratory reagents; this was done by the administration of COMSATS University of Islamabad. Addis Ababa University and Wolkite University have covered costs for sample collection of this study.

\section{Availability of data and materials}

Information-related sample collection and GPS data (Supplementary Table 1) and microsatellite genotypic data (Supplementary Table 2) of date palms are available with a manuscript as additional files. During acceptance of this article, all data that support the finding of this study should be archived in figshare repository.

\section{Declarations}

Ethics approval and consent to participate

Not applicable

Consent for publication

Not applicable

\section{Competing interests}

The authors declare that they have no competing interests.

\section{Author details}

${ }^{1}$ Institute of Biotechnology, Addis Ababa University, Addis Ababa, Ethiopia. ${ }^{2}$ Department of Biology, Wolkite University, Wolkite, Ethiopia. ${ }^{3}$ Ethiopian Biotechnology Institute (EBTi), Ministry of Science and Technology (MoST), Addis Ababa, Ethiopia. ${ }^{4}$ Department of Biosciences, COMSATS University of Islamabad, Islamabad, Pakistan.

Received: 5 January 2021 Accepted: 15 April 2021

Published online: 07 May 2021

References

1. Flowers JM, Hazzouri KM, Gros-Balthazard M, Mo Z, Koutroumpa K, Perrakis A, Ferrand S, Khierallah HSM, Fuller DQ, Aberlenc F, Fournaraki C, Purugganan MD (2019) Cross-species hybridization and the origin of North African date palms. PNAS 116(5):1651-1658

2. Mirbahar AA, Markhand GS, Khan S, Abul-Soad AA (2014) Molecular characterization of some Pakistani date palm (Phoenix dactylifera L.) cultivars by RAPD markers. Pak J Bot 46(2):619-625 
3. Bodian A, Nachtigall M, Frese L, Elhoumaizi MA, Hasnaoui A, Ndir KN, Wehling P (2012) Genetic diversity analysis of date palm (Phoenix dactylifera L.) Cultivars from Figuig oasis (Morocco) using SSR markers. Int J Sci Adv Tech 2(3):1-9

4. Karim K, Ines R, Souhayla M, Khayria H (2015) Morphological and molecula evaluation of the genetic diversity of Tunisian local date palm pollinators. Acad J Biotech 3(2):026-034. https://doi.org/10.15413/ajb.2015.0113 ISSN 2315-7747

5. Du B, Ma Y, Yanez-Serrano AM, Arab L, Fasbender L, Alfarraj S, Albasher G, Hedrich R, White PJ, Werner C, Rennenberg H (2020) Physiological responses of date palm (Phoenix dactylifera) seedlings to seawater and flooding. New Phytol:1-12. https://doi.org/10.1111/nph.17123

6. Kurup SS, Aly MAM, Lekshmi G, Tawfik NH (2014) Rapid in vitro regeneration of date palm (Phoenix dactylifera L.) cv. Kheneizi using tender leaf explants. Emir J Food Agric 26(6):539-544. https://doi.org/10.9755/ejfa.v26i6.18051 http://www.ejfa.info/

7. Johnson DV (2012) Enhancement of date palm as a source of multiple products: examples from other industrialized palms. Emir J Food Agric 24(5): 408-414 http://ejfa.info/

8. El-Far AH, Shaheen HM, Abdel-Daim MM, Al-Jaouni SK, Mousa SA (2016) Date palm (Phoenix dactylifera L.): protection and remedy food - review article. Curr Trends Nutracetucal 1(2):1-10

9. Aljaloud S, Colleran HL, Ibrahim SA (2020) Nutritional value of date fruits and potential 8 use in nutritional bars for athletes. Food Nutr Sci 11:463480. https://doi.org/10.4236/fns.2021.122009

10. Fatima G, Khan IA, Buerkert A (2016) Socio-economic characterisation of date palm (Phoenix dactylifera L.) growers and date value chains in Pakistan. SpringerPlus 5(1222):1-13. https://doi.org/10.1186/s40064-016-2855-4

11. Al-Jabri T (2014) The date palm: a special plant from the old world Tropical Biodiversity, https://wordpress.org/

12. El Hadrami A, Al Khayri JM (2012) Socioeconomic and traditional importance of date palm. Emir J Food Agric 24:371-385 http://ejfa.info

13. Khiari R, Mauret E, Belgacem MN, Mhemmi F (2011) Tunisian date palm rachis used as an alternative source of fibers for papermaking applications. BioResources 6(1):265-281

14. Simon H (1978) The date palm-bread of the desert. Dodd, Mead (1978) ISBN 10: 0396075231 ISBN 13: 9780396075233.

15. Mariana G (2007) The Assyrian sacred tree: a history of interpretations. AcademicNandenhoeck Ruprecht, Zurich Open Repository and Archive University of Zurich, Fribourg, Göttingen, pp 12-325

16. Chao CCT, Krueger RR (2007) The date palm (Phoenix dactylifera L.): overview of biology, uses and cultivation. Hortic Sci 42(5):1-6

17. Amom T, Nongdam P (2017) The use of molecular marker methods in plants: a review. Int J Cur Res Rev 9(17):1-7. https://doi.org/10.7324/IJCRR.2 017.9171

18. Lemlem A, Alemayehu M, Endris M (2018) Date palm production practices and constraints in the value chain in Afar Regional State, Ethiopia. In: Hindawi Advances in Agriculture. https://doi.org/10.1155/2018/6469104

19. Hussen $\mathrm{AH}$ (2010) Potential of date palm plantation in Afar region, Ethiopia and its market. ISHS Acta Horticulturae, 882: IV International Date Palm Conference. Dol: https://doi.org/10.17660/ActaHortic.2010.882.3

20. Ben-Salah M (2015) Date palm status and perspective in sub-Sahelian African countries: Burkina Faso, Chad, Ethiopia, Mali, Senegal, and Somalia. In: Al-Khayri JM, Jain SM, Johnson DV (eds) Date Palm Genetic Rsources and Utilization. Springer Science + Business Media, Springer, Dordrecht, pp 369-586

21. Salomon-Torres R, Ortiz-Uribe N, Villa-Angulo C, Villa-Angulo R, YaurimaBasaldúa VH (2017) Assessment SSR markers used in analysis of genetic diversity of date palm (Phoenix dactylifera L.). Plant Cell Biotechnol Mol Biol 18(5\&6):269-280

22. El-Assar AM, Krueger RR, Devanand SP, Chao TC-C (2005) Genetic analysis of Egyptian date (Phoenix dactylifera L.) accessions using AFLP markers. Genet Resour Crop Evol 52:601-607. https://doi.org/10.1007/s10722-004-0583-z

23. Abd-Alla MM (2010) Genetic stability on Phoenix dactylifera var. Karama produced in Vitro. New York Sci J 3(12):1-7

24. Zehdi S, Trifi M, Billotte N, Marrakchi M, Pintaud JC (2004) Genetic diversity of Tunisian date palms (Phoenix dactylifera L.) revealed by nuclear microsatellite polymorphism. Hereditas 141:278-287

25. Yusuf AO, Culham A, Aljuhani W, Ataga CD, Hamza AM, Odewale JO, Enaberue LO (2015) Genetic diversity of Nigerian date palm (Phoenix dactylifera L.) germplasm based on microsatellite markers. Int J Bio-SC BioTech 7(1):121-132
26. Haider N, Nabulsi I, MirAli N (2012) Phylogenetic relationships among date palm (Phoenix dactylifera L.) cultivars in Syria using RAPD and ISSR markers. J Plant Bio Res 1(2):12-24 ISSN: 2233-0275 http://www.inast.org/jpbr.html

27. Billotte N, Marseillac P, Brottier P, Noyer JL, Jacquemoud JP, Moreau C, Couvreur TLP, Chavallier MH, Pintaud JC, Risterucci AM (2004) Nuclear microsatellite markers for the date palm (Phoenix dactylifera L.): characterization and utility across the genus Phoenix and in other palm genera. Mol Ecol Notes 4ISSN 1471-8278:256-258

28. Yeh FC, Yang R-c, Boyle T (2009) Microsoft Windows-based freeware for population genetic analysis-POPGENE VERSION 1.31

29. Peakall R, Smouse PE (2012) GenAlEx 6.5: genetic analysis in Excel. Population genetic software for teaching and research - an update. Bioinformatics 28:2537-2539 http://bioinformatics.oxfordjournals.org/ content/28/19/2537

30. Pritchard JK, Stephens M, Donnelly P (2000) Inference of population structure using multilocus genotype data. Genetics 155:945-959

31. Evanno G, Regnaut S, Goudet J (2005) Detecting the number of clusters of individuals using the software STRUCTURE: a simulation study. Mol Ecol 14: 2611-2620. https://doi.org/10.1111/j.1365-294X.2005.02553.x

32. Earl DA, VonHoldt BM (2012) Structure Harvester: a website and program for visualizing STRUCTURE output and implementing the Evanno method. Conserv. Genet Res 4:359-361

33. Jakobsson M, Rosenberg NA (2007) CLUMPP: a cluster matching and permutation program for dealing with label switching and multimodality in analysis of population structure. Bioinformatics 23(14):1801-1806 http:// rosenberglab.bioinformatics.med.umich.edu/clumpp.html3

34. Jombart T, Devillard S, Balloux F (2010) Discriminant analysis of principal components: a new method for the analysis of genetically structured populations. BMCGenet. 11(1):1-15

35. Jombart T (2008) adegenet: a R package for the multivariate analysis of genetic markers. Bioinformatics. 24(11):1403-1405

36. Ohta T (1982) Linkage disequilibrium due to random genetic drift in finite subdivided populations. Proc Natl Acad Sci USA 79:1940-1944

37. Ohta T (1982) Linkage disequilibrium with the island model. Genetics 101: 139-155

38. Khierallah HSM, Bader SM, Baum M, Hamwieh A (2011) Genetic diversity of Iraqi date palms revealed by microsatellite polymorphism. J Amer Soc Hort Sci 136(4):282-287. https://doi.org/10.21273/JASHS.136.4.282

39. Zehdi-Azouzi S, Cherif E, Moussouni S et al (2015) Genetic structure of the date palm (Phoenix dactylifera L.) in the Old World reveals a strong differentiation between eastern and western populations. Ann Bot 116:101112

40. Aljuhani WS (2016) Genetic diversity and the impact of geographical location on the relationships between Phoenix dactylifera L. germplasms grown in Saudi Arabia. Hereditary Genet 5(172):1-11

41. Chaluvadi SR, Young P, Thompson K, Bahri BA, Gajera B, Narayanan S, Krueger R, Bennetzen JL (2019) Phoenix phylogeny and analysis of genetic variation in a diverse collection of date palm (Phoenix dactylifera) and related species. Plant Divers 41:330-339. https://doi.org/10.1016/j.pld.201 8.11 .005

42. Racchi ML, Bove A, Turchi A, Bashir G, Battaglia M, Camussi A (2014) Genetic characterization of Libyan date palm resources by microsatellite markers. 3 . Biotech 4:21-32. https://doi.org/10.1007/s13205-013-0116-6

43. Moussouni S, Pintaud J-C, Vigouroux Y, Bouguedoura N (2017) Diversity of Algerian oases date palm (Phoenix dactylifera L., Arecaceae): heterozygote excess and cryptic structure suggests farmer management had a major impact on diversity. PLoS One 12(4):e0175232

44. He Z, Zhang C, Liu W, Lin Q, Wei T, Aljohi HA, Chen W-H, Hu S (2017) DRDB: an online date palm genomic resource database. Front Plant Sci 8:1889. https://doi.org/10.3389/fpls.2017.01889

45. Miller JM, Cullingham Cl, Peery RM (2020) The influence of a priori grouping on inference of genetic clusters: simulation study and literature review of the DAPC method. Heredity 125:269-280. https://doi.org/10.1038/s41437-02 0-0348-2

46. Oliveira EJ, Pádua JG, Zucchi MI, Vencovsky R, Vieira MLC (2006) Origin, evolution and genome distribution of microsatellites. Genet Mol Biol 29(2): 294-307

47. Hosseinzadeh-Colagar A, Haghighatnia MJ, Amiri Z, Mohadjerani M, Tafrihi M (2016) Microsatellite (SSR) amplification by PCR usually led to polymorphic bands: evidence which shows replication slippage occurs in extend or nascent DNA strands. Mol Biol Res Commun 5(3):167-174 
48. LoveLess MD, Hamrick JL (1984) Ecological determinants of genetic structure in plant populations. Annu Rev Ecol Syst 15:65-95

49. Charlesworth D (2006) Evolution of plant breeding systems-review. Curr Biol 16:726-735

50. Rao VR, Hodgkin T (2002) Genetic diversity and conservation and utilization of plant genetic resources. Plant Cell Tissue Organ Cult 68:1-19

\section{Publisher's Note}

Springer Nature remains neutral with regard to jurisdictional claims in published maps and institutional affiliations.

Submit your manuscript to a SpringerOpen ${ }^{\circ}$ journal and benefit from:

- Convenient online submission

- Rigorous peer review

- Open access: articles freely available online

- High visibility within the field

- Retaining the copyright to your article

Submit your next manuscript at $\boldsymbol{\nabla}$ springeropen.com 